\title{
Evaluation of drilling muds enhanced with modified starch for HPHT well applications
}

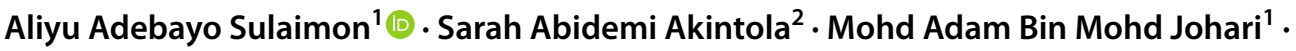 \\ Sunday Oloruntoba Isehunwa ${ }^{2}$
}

Received: 23 July 2019 / Accepted: 17 October 2020 / Published online: 31 October 2020

(c) The Author(s) 2020

\begin{abstract}
The use of carboxymethyl cellulose (CMC) in oil and gas well drilling operations has improved the filtration loss and mud cake properties of drilling muds. The introduction of starch has also reduced, for example, the viscosity, fluid loss, and mud cake properties of the drilling fluids. However, normal starch has some drawbacks such as low shear stress resistance, thermal decomposition, high retrogradation, and syneresis. Hence, starch modification, achieved through acetylation and carboxymethylation, has been introduced to overcome these limitations. In this study, modified starches, from cassava and maize, were used to enhance the properties of water-based muds under high-pressure high temperature (HPHT) conditions, and their performances were compared with that of the CMC. The mud samples added with acetylated cassava or maize starch exhibited the smallest filtrate volumes and filtrate losses within the American Petroleum Institute specification. Therefore, these modified starch-added muds could replace CMC as fluid loss agents since, unlike it, they can withstand HPHT conditions.
\end{abstract}

Keyword Acetylation $\cdot$ Carboxymethylation $\cdot$ Modified starches $\cdot$ CMC $\cdot$ Filtration loss properties $\cdot$ Rheological properties

$\begin{array}{ll}\text { Abbreviations } \\ \text { E\&P } & \text { Exploration and production } \\ \text { HPHT } & \text { High-pressure high temperature } \\ \text { CMC } & \text { Carboxyl-Methyl-Cellulose } \\ \text { AM } & \text { Acetylated maize } \\ \text { CM } & \text { Carboxymethyl maize } \\ \text { AC } & \text { Acetylated cassava } \\ \text { CC } & \text { Carboxymethyl cassava } \\ \text { BHR } & \text { Before hot rolling } \\ \text { AHR } & \text { After hot rolling }\end{array}$

\section{Introduction}

Hydrocarbon exploration has become more challenging, especially during drilling in ultradeep waters and high temperature $\left(>300{ }^{\circ} \mathrm{F}\right)$ high pressure $(\geq 10,000 \mathrm{psi})$ formations. The combined pressure-temperature effect alters

Aliyu Adebayo Sulaimon

aliyu.adebayor@utp.edu.my

1 Department of Petroleum Engineering, Universiti Teknologi PETRONAS, 32610 Bandar Seri Iskandar, Perak, Malaysia

2 Department of Petroleum Engineering, University of Ibadan, Ibadan, Oyo State, Nigeria the rheological properties of the drilling fluids, making the conventional drilling muds ineffective; the consequences include complex phenomena and problems such as formation damage, pipe sticking, sloughing shale, and uncontrollable kicks. Properly designed drilling fluids are required to overcome the challenges posed by high temperature and overpressure formations. Thus, modified starch has been introduced as an additive to reduce or even eliminate the deficiencies of conventional drilling fluids; it can enhance their properties in complex formations.

Drilling operations in unconventional reservoirs such as coal-bed methane and shale ones require appropriate drilling muds to prevent hole problems such as sloughing shale, fluid loss, and formation damage. The viscosity, yield point, and gel strength of the muds decrease as the formation temperature increases with depth. Changes of the mud properties result in thermal degradation of their solid, polymeric, and other components; nevertheless, the introduction of modified starch into water-based muds has reduced the HPHT fluid loss and improved their rheological properties. An optimised drilling fluid can form an effective mud cake able to prevent fluid loss. Furthermore, the mud rheological properties should be stable over a wide range of pressure and temperature to keep the cuttings in suspension when the circulation stops (Okumo and Isehunwa 2007; Sulaimon et al. 2017). 
Starch can serve as an additive capable of enhancing and improving the mud viscosity and also control the fluid loss. It contains two important components: amylose and amylopectin (Taiwo et al. 2011). Amylose helps to enhance the drilling fluid properties, especially, viscosity and fluid-loss control. Sodhi and Singh (2004) reported that Betancur et al. (1997) observed that the normal starch presents limitations such as low shear stress resistance, thermal decomposition, high retrogradation and syneresis that reduce its industrial applicability; to optimise the fluid-loss and viscosity properties, starch requires some modifications. Therefore, this study aimed to modify native starch and use it to reduce fluid loss and stabilise the mud rheological properties in HPHT formations. The three main factors considered were the rheology, the HPHT fluid loss, and the pH of mud samples treated with different modified starches.

Several studies have been conducted in the past. However, most of the earlier studies were based on raw starches obtained from cassava, potato, maize, and guar gum (Aboulrous et al. 2013; Harry et al. 2016; Okumo and Isehunwa 2007; and Taiwo Joel and Kazeem 2011). Results have shown that the CMC outperforms these raw starches.

\section{Materials and methods}

\section{Materials}

In the experiments, the following materials were mainly used: Distilled water, CMC, AC, CC, AM, and CM.

\section{Instruments and procedures}

\section{Starch acetylation}

The acetylated starch was obtained through the method developed by Sodhi and Singh (2005), usually used for similar modifications. Distilled water was used for the dispersion of the starch with a required volume of $450 \mathrm{ml}$ and the mixture was stirred for $1 \mathrm{~h}$ at $30{ }^{\circ} \mathrm{C}$. Then, $3 \% \mathrm{NaOH}$ was added to obtain a suspension $\mathrm{pH}$ of 8.0; simultaneously, acetic anhydride ( $12 \mathrm{~g}$ ) was carefully added to the mixture whilst maintaining the $\mathrm{pH}$ value within the 8.0-8.4 range. The mixing continued for $10 \mathrm{~min}$ and the $\mathrm{pH}$ was adjusted to 4.5 by adding $0.5 \mathrm{M} \mathrm{HCl}$. After sedimentation, the precipitate was washed twice with distilled water and once with 95\% ethanol to remove the acid.

\section{Starch carboxymethylation}

The carboxymethylated starch was obtained via the wet method (Khalil et al. 1990). First, $100 \mathrm{~g}$ of starch was dispersed in an aqueous solution of isopropanol in the 80:20 ratio, followed by $\mathrm{pH}$ adjustment with a $2 \mathrm{M} \mathrm{NaOH}$ solution. Then, monochloroacetic acid $(40 \% \mathrm{wt} / \mathrm{vol})$ was added to the suspension, which was successively incubated at $30{ }^{\circ} \mathrm{C}$ under intermittent stirring. The carboxymethylation process was conducted under a nitrogen atmosphere to avoid polymer degradation.

\section{Rheological properties characterisation}

The rheological properties of the mud were evaluated using a Fann 35 viscometer. Dial readings were taken at six different speeds $(600,300,200,100,6$, and $3 \mathrm{rpm})$ and two different temperatures $\left(80\right.$ and $\left.120^{\circ} \mathrm{F}\right)$. The measurements were conducted also for the modified starches: AM, CM, $\mathrm{AC}$, and $\mathrm{CC}$. Then, after hot rolling the various mud samples for $16 \mathrm{~h}$, the rheological tests were repeated.

\section{HPHT fluid-loss measurement}

For the HPHT fluid test, both temperature and pressure can be varied to represent an expected downhole condition. The HPHT testing equipment has a heating jacket so you can heat up the drilling fluid sample to the expected wellbore temperature. Typically, the recommended temperature in the heating jacket should be above the estimated temperature of about $25 \mathrm{~F}-50 \mathrm{~F}$. The test pressure is normally at $500 \mathrm{psi}$ differential pressure. Normal test conditions are $150 \mathrm{~F}$ and 500 psi differential pressure, and the maximum allowable test temperature is $300 \mathrm{~F}$ with the standard equipment. We ensured that the pressure remains constant throughout the $30 \mathrm{~min}$ test period. The HPHT test is performed for $30 \mathrm{~min}$, just like the API fluid lost test. The HPHT fluid-loss test was performed using an HPHT filter press (Ofite).

\section{Results and discussion}

\section{Changes of amylose and amylopectin contents in starch}

The amylose and amylopectin contents in starch are crucial in increasing the viscosity and reducing the filtration-loss property. The percentages of amylose and amylopectin are, respectively, $22.9 \%$ and $77.1 \%$ in maize starch and $21.07 \%$ and $78.93 \%$ in cassava starch. Before the enhancement of viscosity, filtration-loss property, and mud cake thickness, the native starches were modified via acetylation and carboxymethylation. After these processes, changes in the amylose and amylopectin percentages were observed in both starch types (Tables 1,2,3,4). In particular, as regards the maize starch, the amylose content decreased to $20.36 \%$ in $\mathrm{CM}$ and $20.17 \%$ in $\mathrm{AM}$, whereas the amylopectin one 
Table 1 Amylose and amylopectin contents in carboxymethylated maize starch

\begin{tabular}{lll}
\hline Sample & Amylose (\%) & Amylopectin (\%) \\
\hline Carboxymethylated maize & 20.35 & 79.65 \\
starch & & \\
& 20.37 & 79.63 \\
Mean value & 20.36 & 79.64 \\
\hline
\end{tabular}

Table 2 Amylose and amylopectin contents in acetylated maize starch

\begin{tabular}{lll}
\hline Sample & Amylose (\%) & Amylopectin (\%) \\
\hline Acetylated maize starch & 20.18 & 79.82 \\
& 20.16 & 79.84 \\
Mean value & 20.17 & 79.83 \\
\hline
\end{tabular}

Table 3 Amylose and amylopectin contents in carboxymethylated cassava starch

\begin{tabular}{lll}
\hline Sample & Amylose (\%) & Amylopectin (\%) \\
\hline $\begin{array}{lll}\text { Carboxymethylated cas- } \\
\text { sava starch }\end{array}$ & 22.25 & 77.75 \\
& 22.25 & 77.75 \\
Mean value & 22.25 & 77.75 \\
\hline
\end{tabular}

Table 4 AC amylose and amylopectin contents in acetylated cassava starch

\begin{tabular}{lll}
\hline Sample & Amylose $(\%)$ & Amylopectin (\%) \\
\hline $\begin{array}{l}\text { Acetylated cassava } \\
\text { starch }\end{array}$ & 22.08 & 77.92 \\
& 22.09 & 77.91 \\
Mean value & 22.085 & 77.915 \\
\hline
\end{tabular}

correspondingly increased to $79.64 \%$ and $79.84 \%$. For the cassava starch, the amylose percentage increased to $22.25 \%$ in $\mathrm{CC}$ and $22.085 \%$ in $\mathrm{AC}$, whilst the amylopectin one respectively decreased to $77.75 \%$ and $77.915 \%$.

\section{Rheological properties}

\section{Modified starch rheology}

The rheological properties were investigated to determine which of the modified starches could be a promising industrial additive and an alternative to CMC under HPHT conditions. Ten mud samples, containing different concentrations (5 or $10 \mathrm{~g}$ ) of each additive (AC, CC, AM, CM, or CMC), were formulated and their rheological properties tested
Table 5 Rheology properties of $5 \mathrm{~g}$ before hot rolling (BHR)

\begin{tabular}{lllll}
\hline Initial properties (BHR) & AM & CM & AC & CC \\
\hline 5 g of modified starch & & & & \\
Mud density (ppg) & 8.7 & 8.6 & 8.6 & 8.6 \\
Rheological Properties at: & & & & \\
600 rpm dial reading & 52 & 47 & 54 & 46 \\
300 rpm dial reading & 45 & 39 & 49 & 42 \\
200 rpm dial reading & 39 & 36 & 44 & 38 \\
100 rpm dial reading & 37 & 33 & 42 & 36 \\
6 rpm dial reading & 31 & 26 & 40 & 29 \\
3 rpm dial reading & 31 & 25 & 40 & 28 \\
Plastic Viscosity (cp) & 7 & 8 & 5 & 4 \\
Yield Point (lb/100ft $\left.{ }^{2}\right)$ & 38 & 31 & 44 & 38 \\
10 s Gel (lb/100ft $\left.{ }^{2}\right)$ & 43 & 32 & 49 & 37 \\
10 min Gel (lb/100 $\left.{ }^{2}\right)$ & 63 & 51 & 71 & 55 \\
pH & 8.09 & 8.07 & 8.24 & 8.18 \\
\hline
\end{tabular}

Table 6 Rheology properties of $5 \mathrm{~g}$ after hot rolling (AHR)

\begin{tabular}{lllll}
\hline Properties AHR $\left(302^{\circ} \mathrm{F}\right)$ & $\mathrm{AM}$ & $\mathrm{CM}$ & $\mathrm{AC}$ & $\mathrm{CC}$ \\
\hline 5 g of modified starch & & & & \\
Mud density (ppg) & 8.7 & 8.6 & 8.6 & 8.6 \\
Rheological Properties at: & & & & \\
600 rpm dial reading & 117 & 46 & 65 & 41 \\
300 rpm dial reading & 95 & 37 & 55 & 30 \\
200 rpm dial reading & 86 & 33 & 50 & 27 \\
100 rpm dial reading & 78 & 28 & 46 & 22 \\
6 rpm dial reading & 67 & 22 & 42 & 15 \\
3 rpm dial reading & 67 & 21 & 42 & 15 \\
Plastic viscosity $(\mathrm{cp})$ & 22 & 9 & 10 & 11 \\
Yield point $\left(\mathrm{lb} / 100 \mathrm{ft}{ }^{2}\right)$ & 73 & 28 & 45 & 19 \\
10 s Gel $\left(\mathrm{lb} / 100 \mathrm{ft}^{2}\right)$ & 50 & 18 & 30 & 16 \\
10 min Gel $\left(\mathrm{lb} / 100^{2}\right)$ & 88 & 35 & 60 & 30 \\
$\mathrm{pH}$ & 8.09 & 8.07 & 8.24 & 8.18 \\
\hline
\end{tabular}

under HPHT conditions. Several parameters were tested, including plastic viscosity, gel strength at $10 \mathrm{~s}$ and $10 \mathrm{~min}$, HPHT filtration loss, mud cake thickness and $\mathrm{pH}$; the results are summarised in Tables 5,6,7,8,9,10,11,12,13,14,15,16, $17,18,19,20$.

The rheological properties at different speeds and the gel strength at $10 \mathrm{~s}$ and $10 \mathrm{~min}$ were obtained using a viscometer. The plastic viscosity $\mu_{p}$ and yield point $Y_{P}$ were calculated as follows.

$\mu_{p}=\theta_{600}-\theta_{300}$

$Y_{P}=\theta_{300}-\mu_{p}$ 
Table 7 Rheology properties of $10 \mathrm{~g}$ modified starch BHR

\begin{tabular}{lllll}
\hline Properties initial (BHR) & AM & CM & AC & CC \\
\hline 10 g of modified starches & & & & \\
Mud density (ppg) & 8.6 & 8.6 & 8.6 & 8.7 \\
Rheological Properties at: & & & & \\
600 rpm dial reading & 59 & 51 & 53 & 44 \\
300 rpm dial reading & 55 & 45 & 49 & 38 \\
200 rpm dial reading & 48 & 40 & 42 & 34 \\
100 rpm dial reading & 46 & 37 & 40 & 30 \\
6 rpm dial reading & 38 & 28 & 33 & 24 \\
3 rpm dial reading & 38 & 28 & 33 & 24 \\
Plastic viscosity $\left(\mathrm{cp}^{2}\right.$ & 4 & 6 & 4 & 6 \\
Yield point $\left(\mathrm{lb} / 100 \mathrm{ft}^{2}\right)$ & 51 & 39 & 45 & 32 \\
10 s Gel (lb/100ft $\left.{ }^{2}\right)$ & 52 & 37 & 42 & 37 \\
10 min Gel (lb/100 $\left.{ }^{2}\right)$ & 75 & 49 & 55 & 47 \\
pH & 8.65 & 8.37 & 8.48 & 8.96 \\
\hline
\end{tabular}

Table 8 Rheology properties of $10 \mathrm{~g}$ modified starch AHR

\begin{tabular}{lllll}
\hline Properties AHR $\left(302^{\circ} \mathrm{F}\right)$ & AM & CM & AC & CC \\
\hline 10 g of modified starches & & & & \\
Mud density (ppg) & 8.6 & 8.6 & 8.6 & 8.7 \\
Rheological properties at: & & & & \\
600 rpm dial reading & 40 & 34 & 60 & 56 \\
300 rpm dial reading & 32 & 24 & 49 & 46 \\
200 rpm dial reading & 27 & 19 & 45 & 41 \\
100 rpm dial reading & 21 & 15 & 40 & 36 \\
6 rpm dial reading & 13 & 6 & 34 & 32 \\
3 rpm dial reading & 12 & 6 & 30 & 32 \\
Plastic viscosity $(\mathrm{cp})$ & 8 & 10 & 11 & 10 \\
Yield point $\left(\mathrm{lb} / 100 \mathrm{ft}^{2}\right)$ & 24 & 14 & 38 & 36 \\
10 s Gel (lb/100ft $\left.{ }^{2}\right)$ & 13 & 8 & 30 & 23 \\
10 min Gel $\left(\mathrm{lb} / 100^{2}\right)$ & 22 & 19 & 65 & 53 \\
pH & 8.65 & 8.37 & 8.48 & 8.96 \\
\hline
\end{tabular}

For the samples added with $5 \mathrm{~g}$ of modified starches, $\mathrm{AC}$ and $\mathrm{CC}$ exhibited, respectively, the highest viscosity and lowest viscosity at $600 \mathrm{rpm}$. Figure 5 shows the resulting rheological properties of the mud samples before hot rolling with a roller oven, which was measured again $16 \mathrm{~h}$ after hot rolling at $302{ }^{\circ} \mathrm{F}$ (Table 6).

\section{Effect of starch content}

The rheological properties of the eight mud samples containing the modified starches (AM, CM, AC, or CC) were tested and compared based on their different amounts ( 5 or $10 \mathrm{~g}$ ). The result revealed not much difference for the value of dial reading at $600 \mathrm{rpm}$ for four of the samples added with 5 and $10 \mathrm{~g}$ of modified starch. The highest value was obtained with AC because, after carboxymethylation, it contained the highest amount of amylopectin. Taiwo et al. (2011) reported that the large size and the branched nature of amylopectin reduce the polymer mobility and orientation in an aqueous environment. After hot rolling for $16 \mathrm{~h}, \mathrm{AC}$ still provided the highest value of dial reading at $600 \mathrm{rpm}$.

Tables 7 and 8 summarise the results for the samples added with $10 \mathrm{~g}$ of different modified starches. Before hot rolling, the highest viscosity and lowest viscosity at $600 \mathrm{rpm}$ were obtained with $\mathrm{AM}$ and $\mathrm{CC}$, respectively; however, after hot rolling, AM had decreasing viscosity. This indicates that AM cannot withstand HPHT since similar conditions break the polymer linkage of the starch. Nonetheless, the mud samples added with AC and CC showed an increase in viscosity after hot rolling, probably because their polymer linkage can withstand HPHT.

The abovementioned eight mud samples were also weighed by using a mud balance, revealing the same mud weight of $8.6 \mathrm{ppg}$. This indicates that different contents of modified starch do not affect the mud weight.

\section{Effect of temperature}

The rheological properties of the mud samples were also tested at different temperatures $\left(80\right.$ and $\left.120^{\circ} \mathrm{F}\right)$. Also, the samples were aged in a roller oven at $302^{\circ} \mathrm{F}$ for $16 \mathrm{~h}$ to simulate the high temperature of a wellbore and, hence, investigate the performance of the modified starches in real conditions, including their ability to maintain the polymer chain. Based on Table 9, the rheology value for CMC before and after hot rolling at 80 and $120^{\circ} \mathrm{F}$ was significantly reduced because this polymer degraded after the exposition at $302{ }^{\circ} \mathrm{F}$; at $80{ }^{\circ} \mathrm{F}$, it decreased from 44 to 25 after hot rolling.

In theory, when mud experiences an increase in temperature, the cohesive forces in it are reduced, whereas the
Table 9 Carboxymethylated cellulose $5 \mathrm{~g}$ viscometer reading, BHR and AHR, respectively)

\begin{tabular}{llllllll}
\hline & \multicolumn{7}{l}{ Viscometer reading } \\
\cline { 3 - 7 } & & 600 & 300 & 200 & 100 & 6 & 3 \\
\hline Temperature (BHR) & $80^{\circ} \mathrm{F}$ & 102 & 81 & 70 & 59 & 44 & 44 \\
& $120^{\circ} \mathrm{F}$ & 88 & 71 & 65 & 58 & 57 & 57 \\
Temperature (AHR) & $80^{\circ} \mathrm{F}$ & 58 & 44 & 38 & 32 & 25 & 24 \\
& $120^{\circ} \mathrm{F}$ & 53 & 42 & 36 & 34 & 29 & 29 \\
\hline
\end{tabular}


Table 10 Acetylated maize $5 \mathrm{~g}$ viscometer reading, BHR and AHR, respectively)

Table 11 Carboxymethylated maize $5 \mathrm{~g}$ viscometer reading, BHR and AHR, respectively)

Table 12 Acetylated cassava $5 \mathrm{~g}$ viscometer reading, BHR and AHR, respectively)

Table 13 Carboxymethylated cassava $5 \mathrm{~g}$ viscometer reading, BHR and AHR, respectively)

Table 14 Carboxymethylated cellulose 10 viscometer reading, BHR and AHR, respectively)

Table 15 Acetylated maize $10 \mathrm{~g}$ viscometer reading, BHR and AHR, respectively)

\begin{tabular}{llllllll}
\hline & \multicolumn{7}{l}{ Viscometer reading } \\
\cline { 3 - 7 } & & 600 & 300 & 200 & 100 & 6 & 3 \\
\hline Temperature (BHR) & $80^{\circ} \mathrm{F}$ & 52 & 45 & 39 & 37 & 31 & 31 \\
& $120^{\circ} \mathrm{F}$ & 49 & 41 & 37 & 36 & 32 & 32 \\
Temperature (AHR) & $80^{\circ} \mathrm{F}$ & 117 & 95 & 86 & 78 & 68 & 68 \\
& $120^{\circ} \mathrm{F}$ & 114 & 105 & 94 & 93 & 103 & 104 \\
\hline
\end{tabular}

\begin{tabular}{llllllll}
\hline & \multicolumn{7}{l}{ Viscometer reading } \\
\cline { 3 - 7 } & & 600 & 300 & 200 & 100 & 6 & 3 \\
\hline Temperature (BHR) & $80^{\circ} \mathrm{F}$ & 47 & 39 & 36 & 33 & 26 & 25 \\
& $120^{\circ} \mathrm{F}$ & 46 & 38 & 34 & 33 & 30 & 29 \\
Temperature (AHR) & $80^{\circ} \mathrm{F}$ & 46 & 37 & 33 & 28 & 22 & 21 \\
& $120^{\circ} \mathrm{F}$ & 51 & 45 & 42 & 39 & 38 & 38 \\
\hline
\end{tabular}

\begin{tabular}{llllllll}
\hline & \multicolumn{7}{l}{ Viscometer reading } \\
\cline { 3 - 7 } & & 600 & 300 & 200 & 100 & 6 & 3 \\
\hline Temperature (BHR) & $80^{\circ} \mathrm{F}$ & 54 & 49 & 44 & 42 & 40 & 40 \\
& $120^{\circ} \mathrm{F}$ & 58 & 54 & 49 & 48 & 46 & 46 \\
Temperature (AHR) & $80^{\circ} \mathrm{F}$ & 65 & 55 & 50 & 46 & 42 & 42 \\
& $120^{\circ} \mathrm{F}$ & 64 & 55 & 50 & 49 & 51 & 51 \\
\hline
\end{tabular}

\begin{tabular}{llllllll}
\hline & \multicolumn{7}{l}{ Viscometer reading } \\
\cline { 3 - 7 } & & 600 & 300 & 200 & 100 & 6 & 3 \\
\hline Temperature (BHR) & $80^{\circ} \mathrm{F}$ & 46 & 42 & 38 & 36 & 29 & 28 \\
& $120^{\circ} \mathrm{F}$ & 48 & 44 & 40 & 39 & 34 & 34 \\
Temperature (AHR) & $80^{\circ} \mathrm{F}$ & 41 & 30 & 27 & 22 & 15 & 15 \\
& $120^{\circ} \mathrm{F}$ & 40 & 32 & 28 & 26 & 22 & 22 \\
\hline
\end{tabular}

\begin{tabular}{llllllll}
\hline & \multicolumn{7}{l}{ Viscometer reading } \\
\cline { 3 - 7 } & & 600 & 300 & 200 & 100 & 6 & 3 \\
\hline Temperature (BHR) & $80^{\circ} \mathrm{F}$ & 246 & 186 & 156 & 128 & 74 & 74 \\
& $120^{\circ} \mathrm{F}$ & 186 & 141 & 122 & 115 & 72 & 71 \\
Temperature (AHR) & $80^{\circ} \mathrm{F}$ & 85 & 65 & 54 & 43 & 25 & 25 \\
& $120^{\circ} \mathrm{F}$ & 61 & 44 & 37 & 30 & 21 & 21 \\
\hline
\end{tabular}

\begin{tabular}{llllllll}
\hline & \multicolumn{7}{l}{ Viscometer reading } \\
\cline { 3 - 7 } & & 600 & 300 & 200 & 100 & 6 & 3 \\
\hline Temperature (BHR) & $80^{\circ} \mathrm{F}$ & 59 & 55 & 48 & 46 & 38 & 38 \\
& $120^{\circ} \mathrm{F}$ & 61 & 57 & 48 & 47 & 44 & 44 \\
Temperature (AHR) & $80^{\circ} \mathrm{F}$ & 40 & 32 & 27 & 21 & 13 & 12 \\
& $120^{\circ} \mathrm{F}$ & 48 & 36 & 32 & 28 & 22 & 21 \\
\hline
\end{tabular}


Table 16 Carboxymethilated maize $10 \mathrm{~g}$ viscometer reading, BHR and AHR, respectively)
Table 17 Acetylated cassava $10 \mathrm{~g}$ viscometer reading, BHR and AHR, respectively)

\begin{tabular}{llllllll}
\hline & \multicolumn{7}{l}{ Viscometer reading } \\
\cline { 3 - 7 } & & 600 & 300 & 200 & 100 & 6 & 3 \\
\hline Temperature (BHR) & $80^{\circ} \mathrm{F}$ & 51 & 45 & 40 & 37 & 28 & 28 \\
& $120^{\circ} \mathrm{F}$ & 51 & 45 & 36 & 35 & 29 & 29 \\
Temperature (AHR) & $80^{\circ} \mathrm{F}$ & 34 & 24 & 19 & 15 & 6 & 6 \\
& $120^{\circ} \mathrm{F}$ & 32 & 23 & 20 & 16 & 10 & 10 \\
\hline
\end{tabular}

\begin{tabular}{llllllll}
\hline & \multicolumn{7}{l}{ Viscometer reading } \\
\cline { 3 - 7 } & & 600 & 300 & 200 & 100 & 6 & 3 \\
\hline Temperature (BHR) & $80^{\circ} \mathrm{F}$ & 53 & 49 & 42 & 40 & 33 & 33 \\
& $120^{\circ} \mathrm{F}$ & 57 & 51 & 44 & 43 & 38 & 38 \\
Temperature (AHR) & $80^{\circ} \mathrm{F}$ & 60 & 49 & 45 & 40 & 34 & 34 \\
& $120^{\circ} \mathrm{F}$ & 64 & 54 & 50 & 46 & 44 & 44 \\
\hline
\end{tabular}

\begin{tabular}{llllllll}
\hline & \multicolumn{7}{l}{ Viscometer reading } \\
\cline { 3 - 7 } & & 600 & 300 & 200 & 100 & 6 & 3 \\
\hline Temperature (BHR) & $80^{\circ} \mathrm{F}$ & 44 & 38 & 34 & 30 & 24 & 24 \\
& $120^{\circ} \mathrm{F}$ & 45 & 41 & 34 & 33 & 29 & 29 \\
Temperature (AHR) & $80^{\circ} \mathrm{F}$ & 56 & 46 & 41 & 36 & 32 & 32 \\
& $120^{\circ} \mathrm{F}$ & 54 & 44 & 42 & 39 & 35 & 34 \\
\hline
\end{tabular}

Table 18 Carboxymethylated cassava $10 \mathrm{~g}$ viscometer reading, BHR and AHR, respectively)
Table 19 HTHP filtration loss and mud cake thickness for mud samples with $5 \mathrm{~g}$ of starches

\begin{tabular}{lcl}
\hline Mud sample & \multicolumn{2}{l}{ Test } \\
\cline { 2 - 3 } & $\begin{array}{l}\text { HPHT filtration fluid loss } \\
(\mathrm{ml})\end{array}$ & $\begin{array}{l}\text { Filtrate cake } \\
\text { thickness }(\mathrm{mm})\end{array}$ \\
\hline CMC & $24 \pm 1.0$ & $6.6 \pm 0.1$ \\
$\mathrm{AM}$ & $14 \pm 1.0$ & $9.3 \pm 0.1$ \\
$\mathrm{CM}$ & $31 \pm 1.0$ & $8.6 \pm 0.1$ \\
AC & $25 \pm 1.0$ & $4.7 \pm 0.1$ \\
CC & $26.5 \pm 1.0$ & $4.5 \pm 0.1$ \\
\hline
\end{tabular}

Table 20 HTHP filtration loss and mud cake thickness for mud samples added with $10 \mathrm{~g}$ of starches

\begin{tabular}{lrl}
\hline Mud sample & \multicolumn{2}{l}{ Test } \\
\cline { 2 - 3 } & $\begin{array}{l}\text { HPHT filtration fluid loss } \\
(\mathrm{ml})\end{array}$ & $\begin{array}{l}\text { Filtrate cake } \\
\text { thickness }(\mathrm{mm})\end{array}$ \\
\hline $\mathrm{CMC}$ & $12 \pm 1.0$ & $4.7 \pm 0.1$ \\
$\mathrm{AM}$ & $20.5 \pm 1.0$ & $4.4 \pm 0.1$ \\
$\mathrm{CM}$ & $25.5 \pm 1.0$ & $5.0 \pm 0.1$ \\
$\mathrm{AC}$ & $11 \pm 1.0$ & $6.7 \pm 0.1$ \\
$\mathrm{CC}$ & $23 \pm 1.0$ & $4.7 \pm 0.1$ \\
\hline
\end{tabular}

rate of molecular interchange increases. The cohesive force reduction would affect in decreasing of shear stress whilst the increased rate of molecular interchange would increase the shear stress. At high temperatures, the gas viscosity increases due to the kinetic energy gained by the particles from the increasing temperature, whereas the viscosity in the liquid decreased with the drag force. Under normal room conditions, the molecular structure of the liquid is strongly bonded by the van der Waals intermolecular interactions, which restrict its mobility. However, if the temperature is high enough, the bonds get broken because the particles have gained enough energy to break down the intermolecular forces, increasing mobility. Therefore, the performance of a mud sample treated with modified starch should be theoretically influenced by increasing the temperature.

Figures 1 and 2 show an increasing trend for the mud samples added with AM or AC after hot rolling, indicating that the polymer in these modified starches can withstand high temperatures. As a consequence, their retained polymer bonds and, hence, the increased cohesive forces resulted in increased viscosity. Conversely, the samples added with $\mathrm{CC}$ and $\mathrm{CM}$ showed a decreasing trend in viscosity, meaning that their polymer cannot withstand high temperatures. However, when $10 \mathrm{~g}$ of additive was used, the samples added with $\mathrm{AM}$ and $\mathrm{CM}$ showed a decrease in viscosity after hot rolling, whilst those containing $\mathrm{AC}$ and $\mathrm{CC}$ exhibited a 
Fig. 1 Rheological behaviour at $80{ }^{\circ} \mathrm{F}$ of mud samples added with $5 \mathrm{~g}$ of different modified starches

\section{BHR and AHR of $5 \mathrm{~g}$ Modified Starch Rheological Behavior Comparison At $80^{\circ} \mathrm{F}$}

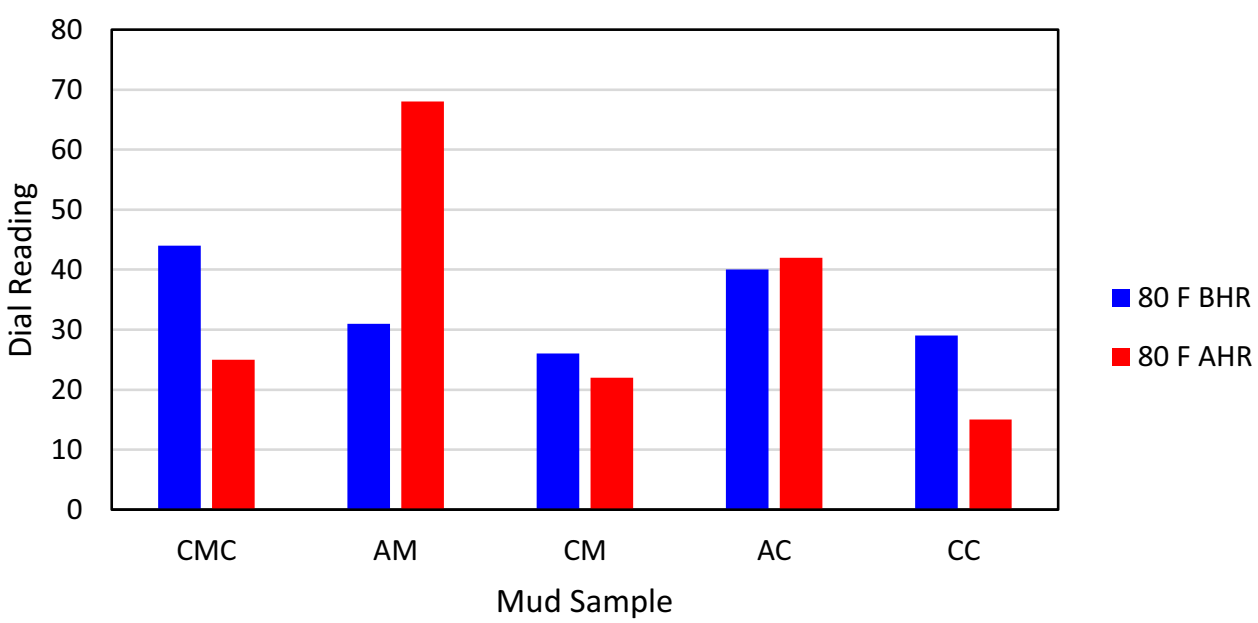

Fig. 2 Rheological behaviour at $120^{\circ} \mathrm{F}$ of mud samples added with $5 \mathrm{~g}$ of different modified starches

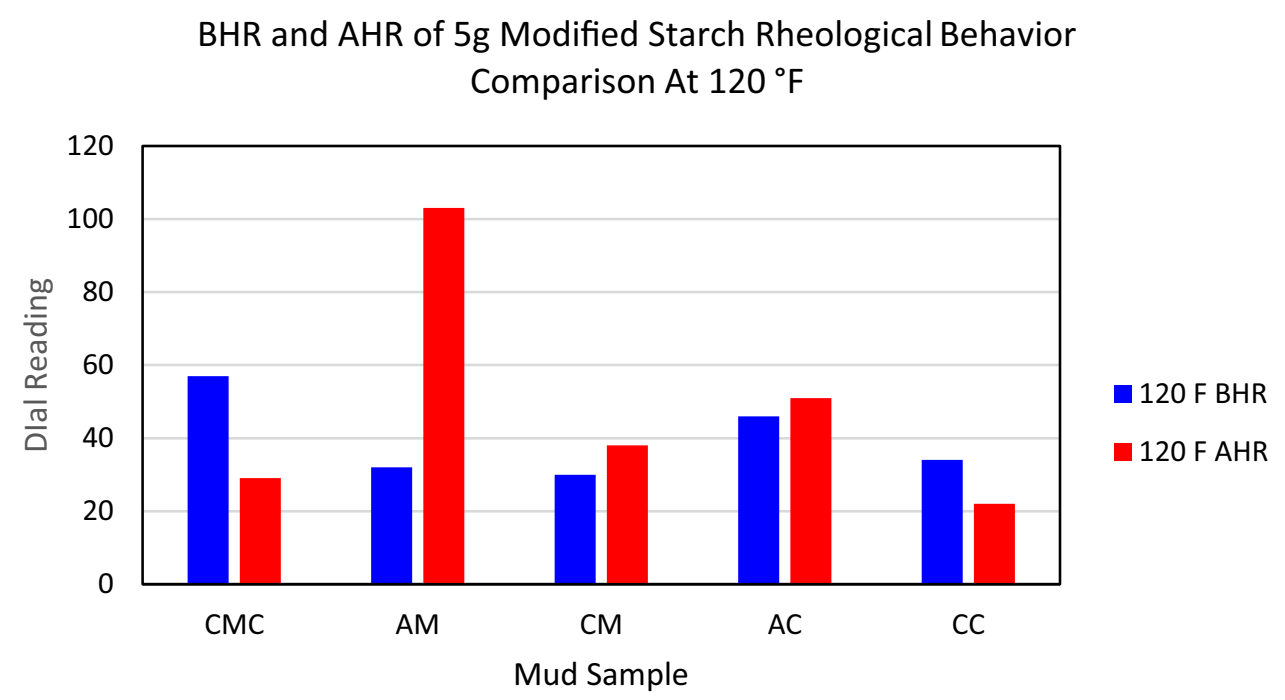

corresponding increase (Figs. 3 and 4). Hence, the highest increment after hot rolling was achieved with $5 \mathrm{~g}$ of $\mathrm{AM}$ as well as $10 \mathrm{~g}$ of $\mathrm{AC}$, which identifies $\mathrm{AM}$ and $\mathrm{AC}$ as promising HPHT fluid-loss agents to replace CMC since this polymer, under HPHT conditions, degrades and its use results in decreased viscosity, affecting also the ability to suspend and remove cuttings.

\section{Plastic viscosity}

The plastic viscosity indicates the solid control, whereby an increase in value showing increase in solid volume or decrease in particle size. It also represents the ability of suspension of drilled cuttings and hole cleaning under dynamic conditions. An increase in the solid content of drilling mud results in higher $\mu_{p}$.
Figure 5 shows that for the $5 \mathrm{~g}$ of additives after hot rolling, the plastic viscosity $\left(\mu_{p}\right)$ decreases for CMC, whilst the $\mathrm{AM}, \mathrm{CM}, \mathrm{AC}$, and $\mathrm{CC}$ exhibited a corresponding increase, indicating that they can withstand HPHT conditions. In particular, AM resulted in the highest increment, in agreement also with the highest absolute value. This suggests that AM had a high solid content, which limited the mudflow and, consequently, increased both the viscosity and plastic viscosity. Besides, amongst the modified starches tested, AM presented the highest amylopectin percentage $(79.83 \%$ ) after the acetylation. The role of amylopectin in starch, as previously discussed, is to reduce the polymer mobility and orientation in aqueous environments. Also, AM had the highest.

For the $10 \mathrm{~g}$ of additives, Fig. 6 shows increased values for all the modified starches after hot rolling. This means that, after being exposed to high pressure and temperature, 
Fig. 3 Rheological behaviour at $80{ }^{\circ} \mathrm{F}$ of mud samples added with $10 \mathrm{~g}$ of different modified starches

\section{BHR and AHR of $10 \mathrm{~g}$ Modified Starch Rheological Behavior}

Comparison At $80^{\circ} \mathrm{F}$

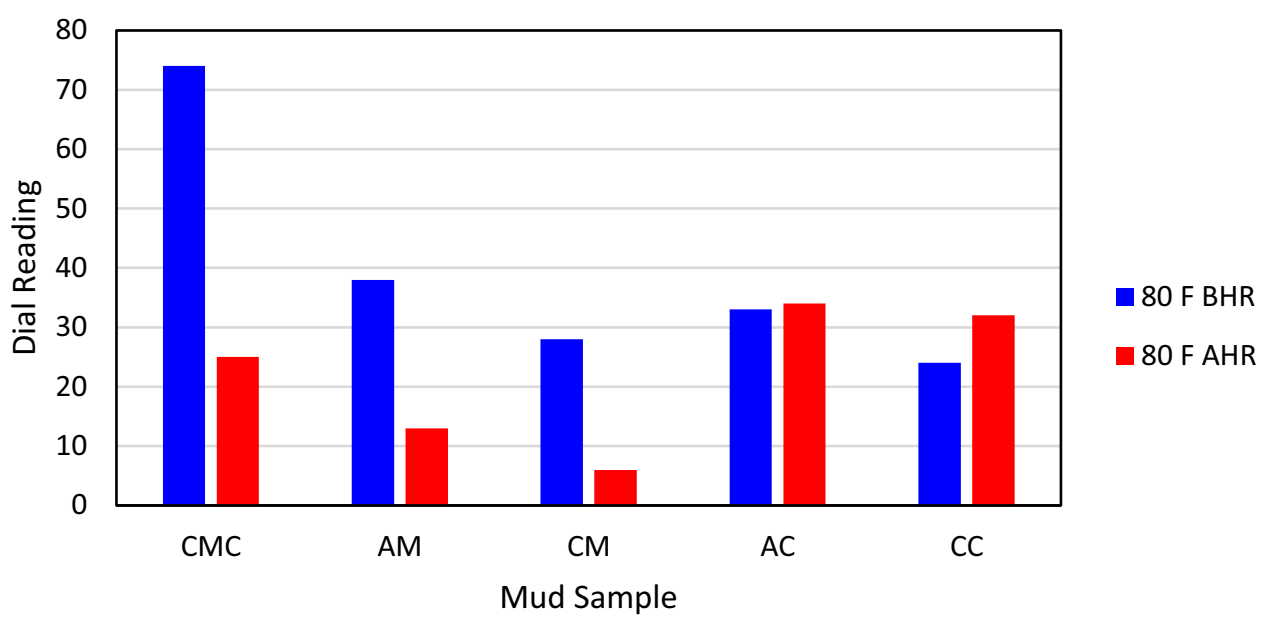

BHR and AHR of $10 \mathrm{~g}$ Modified Starch Rheological Behavior Comparison At $120^{\circ} \mathrm{F}$

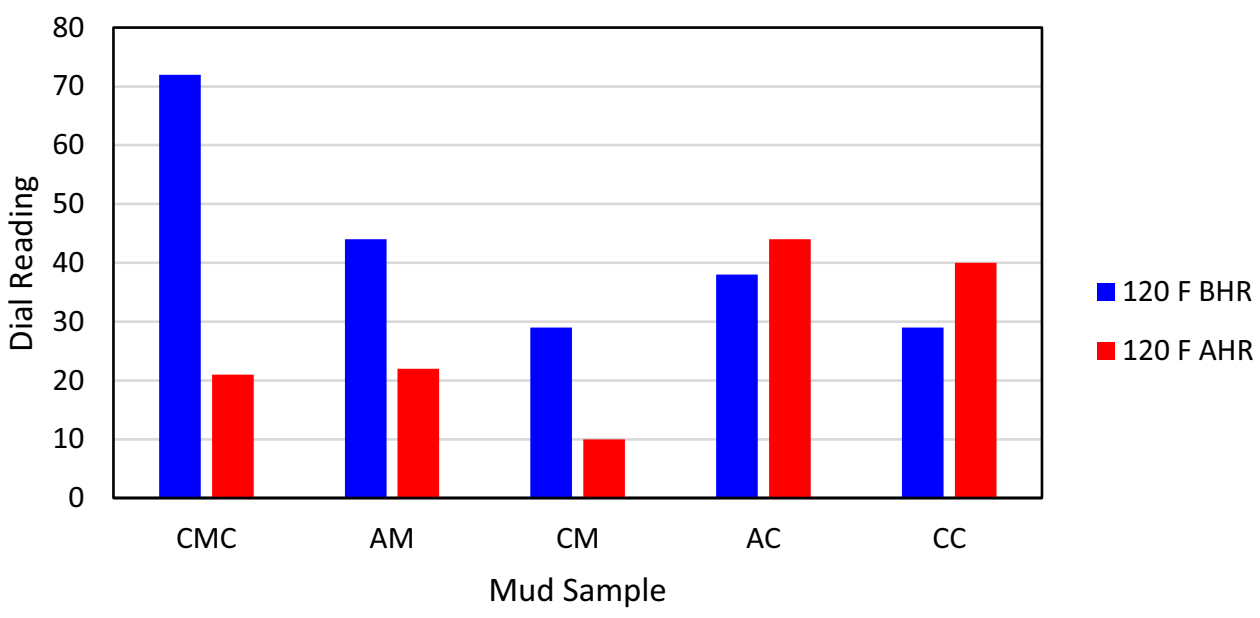

the mud samples with the additives could still suspend the drilled cuttings and perform the hole cleaning. The American Petroleum Institute $(2009,2010)$ specification for high-performance classification is below $35 \mathrm{cp}$. All the mud samples treated with the modified starches exhibited $\mu_{p}$ values below $35 \mathrm{cp}$. This is to minimise the risk of differential sticking, to reduce the low penetration rate and the equivalent circulating density as well as to control the high surge and the swab pressure.

\section{Yield point}

The yield point indicates the ability of the mud to lift the cuttings from the wellbore to the surface. The API specification for high-performance muds is $15-25 \mathrm{cp}$. In theory, the higher the $Y_{P}$, the better the cutting lifting ability. However, an excessive $Y_{P}$ value would lead to a higher pressure loss during the circulation of drilling mud. The results of $5 \mathrm{~g}$ show that the sample added with AM exhibited the highest $Y_{P}$ value after hot rolling, followed by that with $\mathrm{AC}$, whilst a corresponding reduction was observed in the mud containing $\mathrm{CMC}, \mathrm{CC}$, and 
Fig. 5 Plastic viscosity of mud samples added with $5 \mathrm{~g}$ of different modified starches
Plastic Viscosity for 5 gram of additives

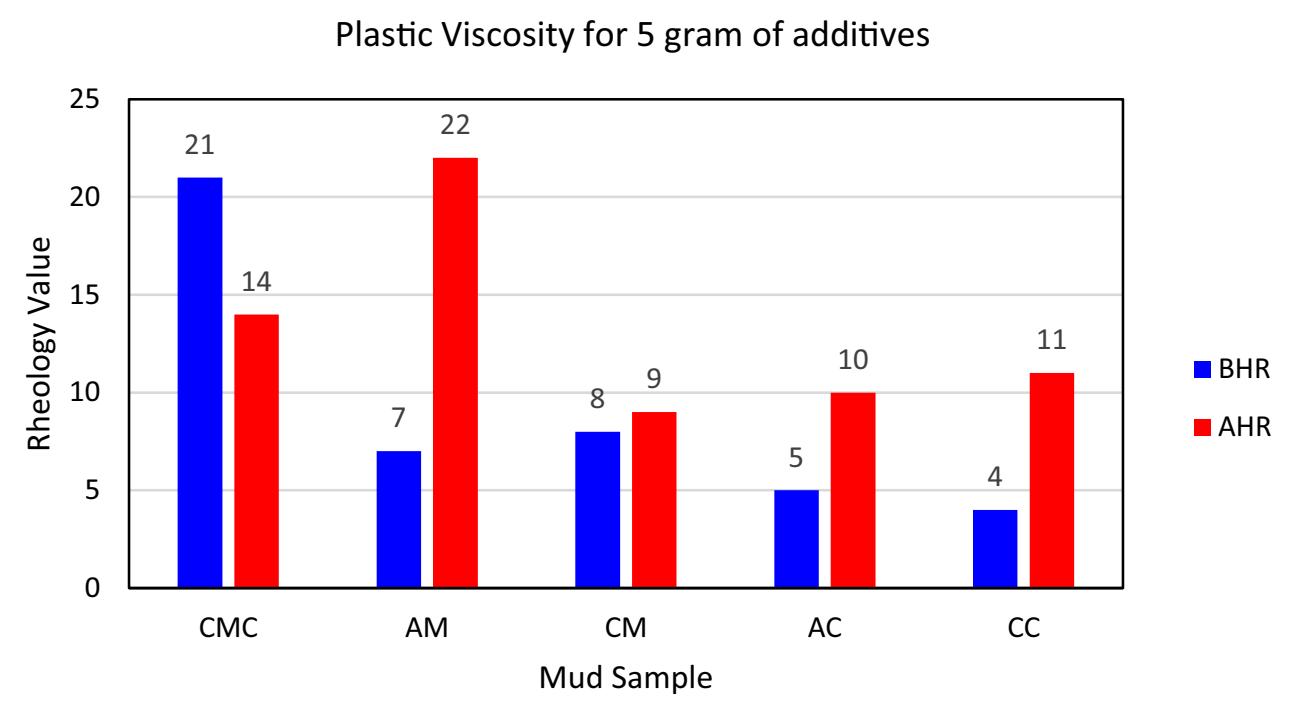

Plastic Viscosity for 10 gram of additives

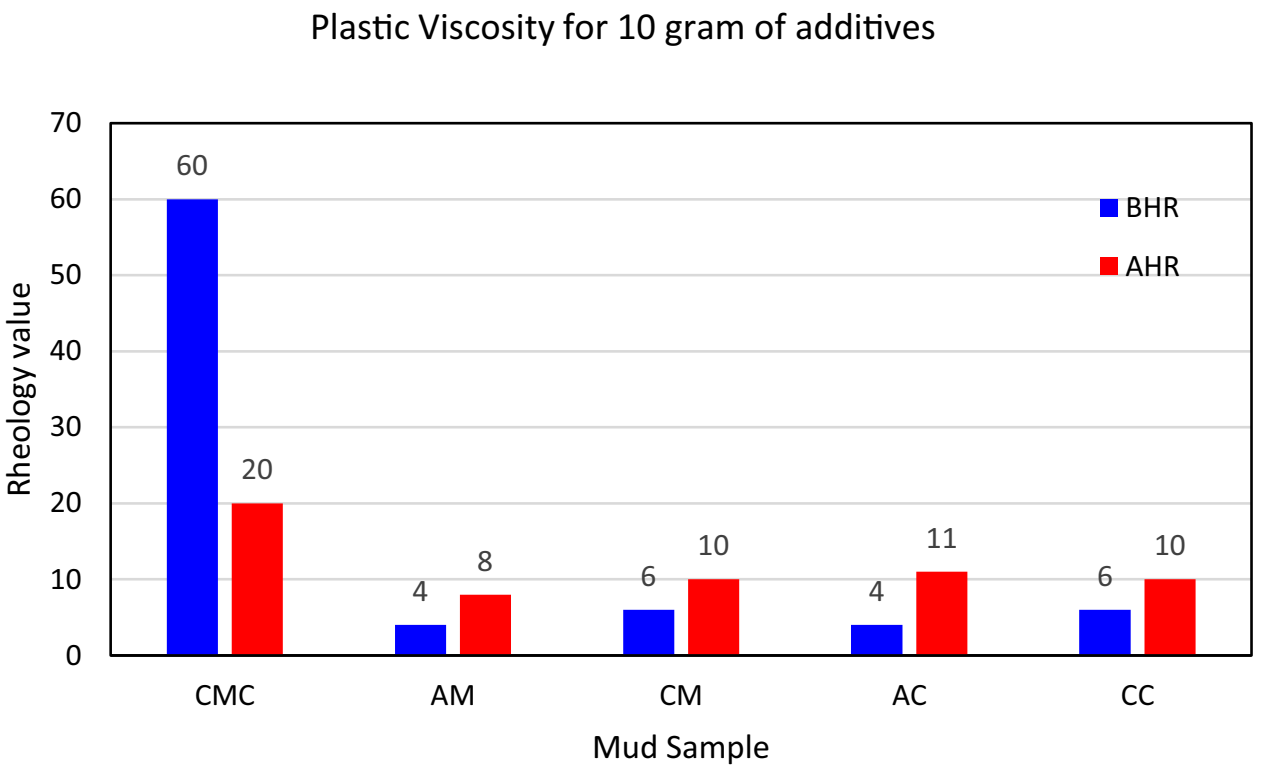

Fig. 6 Plastic viscosity of mud samples added with $10 \mathrm{~g}$ of different modified starches
$\mathrm{CM}$ (Fig. 7). Therefore, the ability of AM and AC to lift the cuttings from the wellbore to the surface increased after the hot rolling; this was probably due to their gelling properties improved by their amylose content, before the acetylation. However, as regards the samples added with $10 \mathrm{~g}$ of different modified starches, only the one with CC exhibited increased $Y_{P}$ after hot rolling, whilst the remaining samples showed a corresponding decrease as shown in Fig. 8. The reason is that the polymer bonding specifically linear and branched inside of the $\mathrm{CC}$ which is amylose and amylopectin could withstand the HPHT; the retained linkage led to this increment after hot rolling. The CMC, AC, $\mathrm{AM}$, and $\mathrm{CM}$ polymer, on the contrary, could not withstand the HPHT, resulting in a $Y_{P}$ reduction.

\section{Gel strength}

The gel strength indicates the capability of mud to hold cuttings in suspension under static conditions. The API specification for the difference between $10 \mathrm{~s}$ and $10 \mathrm{~min}$ gel strength is 20 . When the difference exceeds 20 , more pump power is needed to start the circulation after the static condition. As illustrated in Figs. 9 and 10, only the mud sample added with AM exhibited an increase after hot rolling, whilst the others showed a corresponding reduction after $10 \mathrm{~s}$. Nevertheless, the difference between the gel strengths at $10 \mathrm{~min}$ and $10 \mathrm{~s}$ for AM exceeded 20, hence, more pump power would be required to initiate the circulation. This was similarly observed for CMC and AC. However, the samples added with $\mathrm{CM}$ and $\mathrm{CC}$ showed a lower 
Fig. 7 Yield point of mud samples added with $5 \mathrm{~g}$ of different modified starches
Yield Point for 5 gram of additives

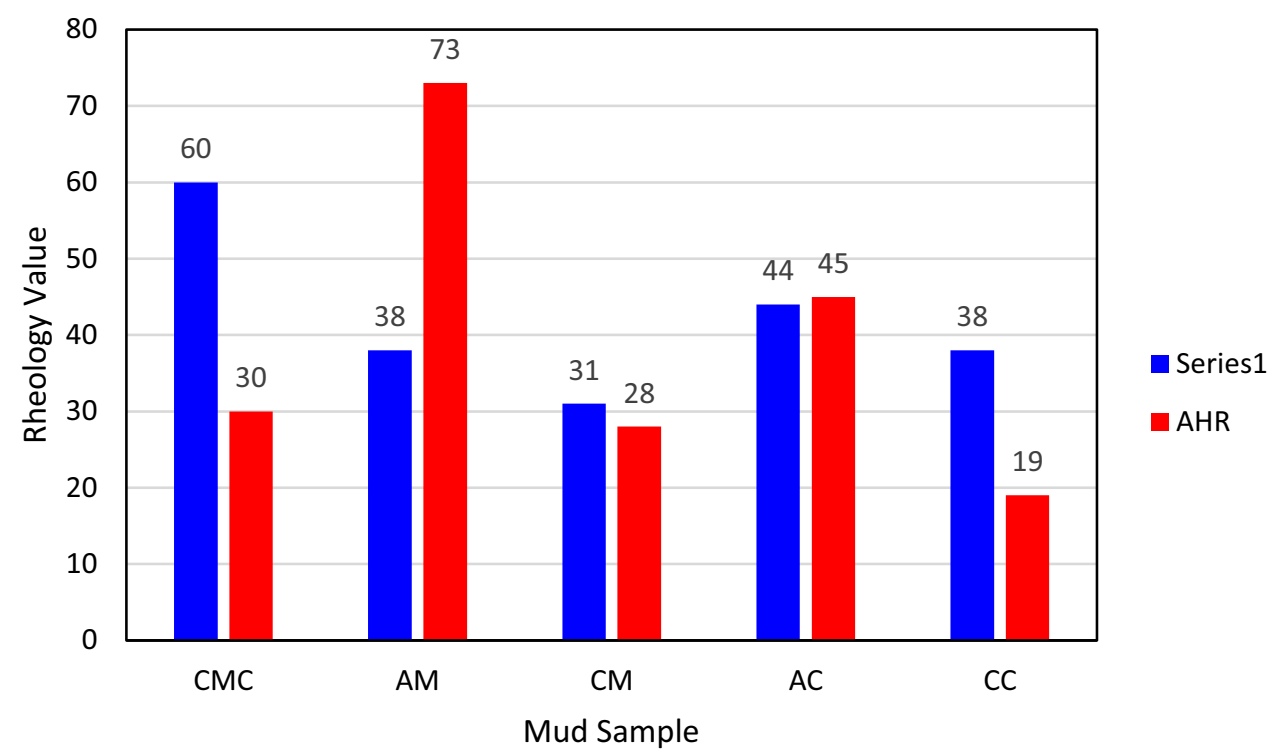

Yield Point for 10 grams of additives

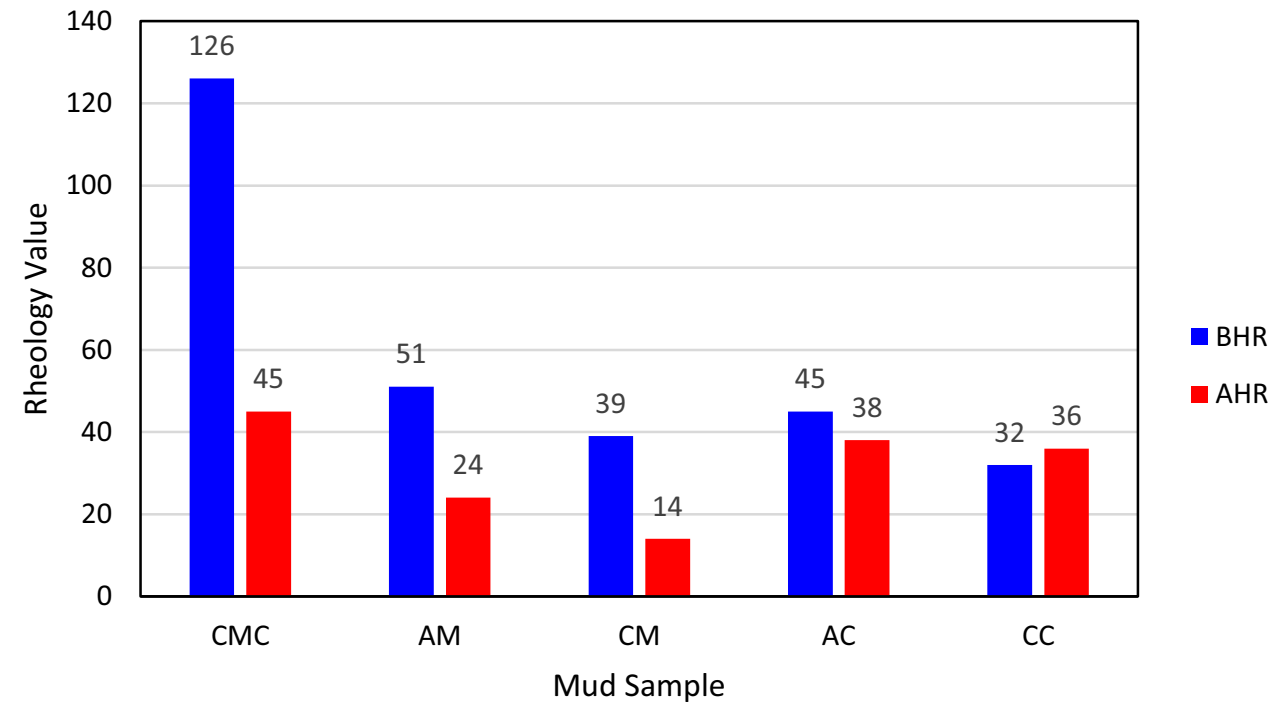

gel strength difference and, consequently, less pump power would be required to restart circulation required because the carboxymethylation process had reduced the molar mass of the starch (Manal 2010).

\section{Filtration loss and mud cake properties}

The filtration loss and mud cake properties of the samples were evaluated via HPHT filtration tests at 1000 psi and $302{ }^{\circ} \mathrm{F}$ for $30 \mathrm{~min}$. The filtration loss test measures the quantity of water leaked out from the drilling mud under simulated high pressure. This water represents the fluid that penetrates the permeable formation during circulation or under static conditions. The mud or filter cake is the thin impermeable wall formed at the opening between the wellbore and the reservoir. The cake limits the possible fluid loss into the formation, which could otherwise damage the wellbore and, thus, reduce the effective permeability of the near-wellbore region.

The maximum API threshold for filtrate loss in waterbased muds is $15 \mathrm{ml}$. If the filtrate volume exceeds this value, there is a risk of clay swelling at the sensitive zone and consequent formation damage, which could reduce the permeability of the area. The HPHT tests showed that only 
Fig. 9 Gel strength at $10 \mathrm{~s}$ of mud samples added with different modified starches
Gel Strength of muds with additives at 10 s

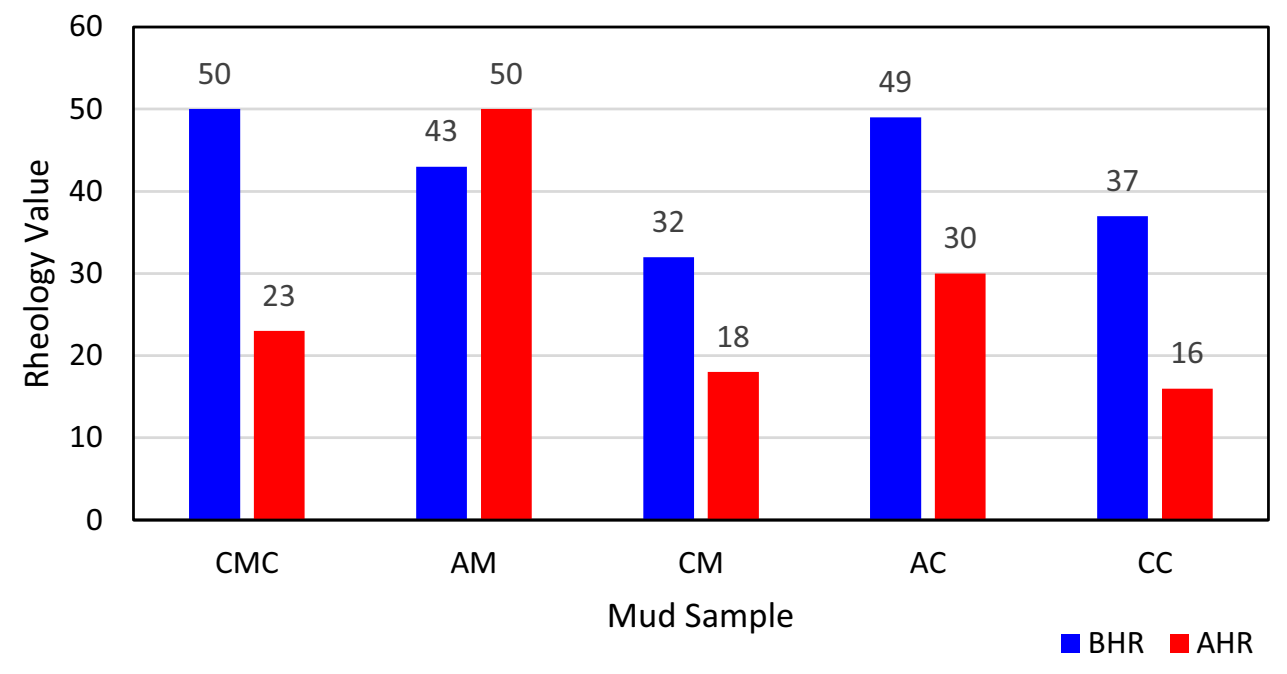

Fig. 10 Gel strength at $10 \mathrm{~s}$ and $10 \mathrm{~min}$, AHR, of mud samples added with different modified starches

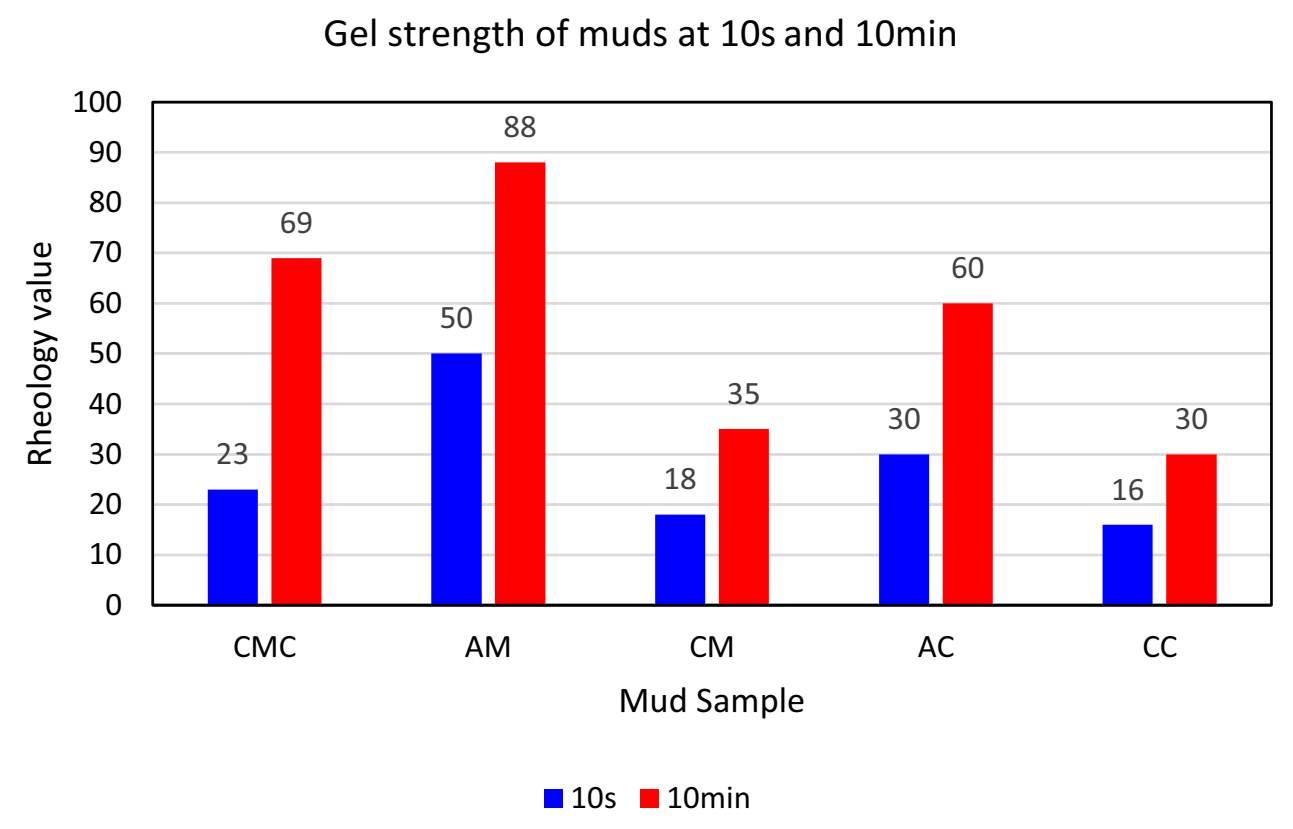

the AM-added sample exhibited a value $(14 \mathrm{ml})$ close to the API specification. However, amongst the samples added with $10 \mathrm{~g}$ of modified starch, the sample with the AC showed the lowest filtrate volume $(11 \mathrm{ml})$.

The mud cake observation revealed that, when using $5 \mathrm{~g}$ of modified starch, the $\mathrm{CC}$ and the AM resulted in, respectively, the smallest and largest cake thickness (Fig. 11). For the samples added with $10 \mathrm{~g}$ of modified starch, the largest and smallest thicknesses were obtained with the AC and AM, respectively, as shown in Fig. 12. This indicates that mud added with $5 \mathrm{~g}$ of $\mathrm{AM}$ or $10 \mathrm{~g}$ of $\mathrm{AC}$ can be compressed despite the strong polymer linkage and the high solid content, which could even reduce the filtrate amount.

\section{Environmental assessment of the mud added with modified starch}

The results displayed in Figs. 13 and 14 show that the eight mud samples added with the different modified starches (5 and $10 \mathrm{~g}$ ) were alkaline, with $\mathrm{pH}$ values above 7 , indicating that the starch reduced the water hardness, which results in the observed $\mathrm{pH}$ increase. In other words, the starch polymer precipitated the calcium ions in the water, increasing the 
Fig. 11 Filtrate characteristics, AHR, of mud samples added with $5 \mathrm{~g}$ of different modified starches
Filtrate Characteristics AHR for 5 gram modified starch

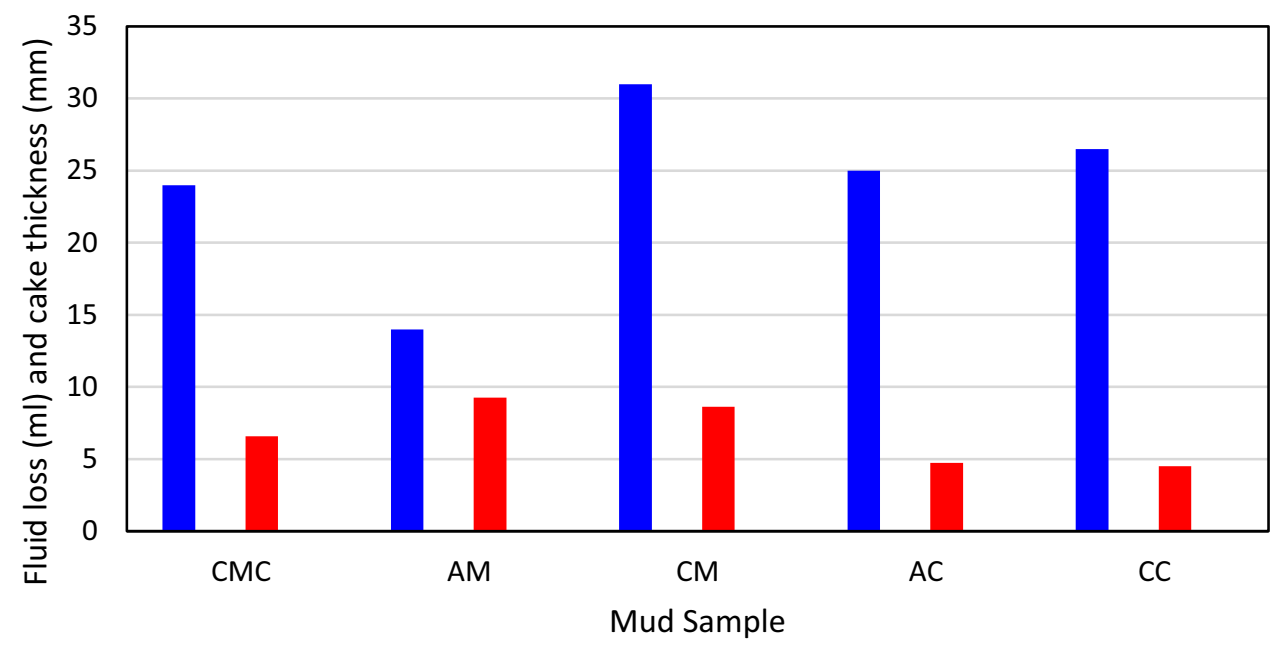

- HPHT filtration fluid loss, ml a Filtate cake thickness, mm

Filtrate Characteristics AHR for 10 gram modified starch

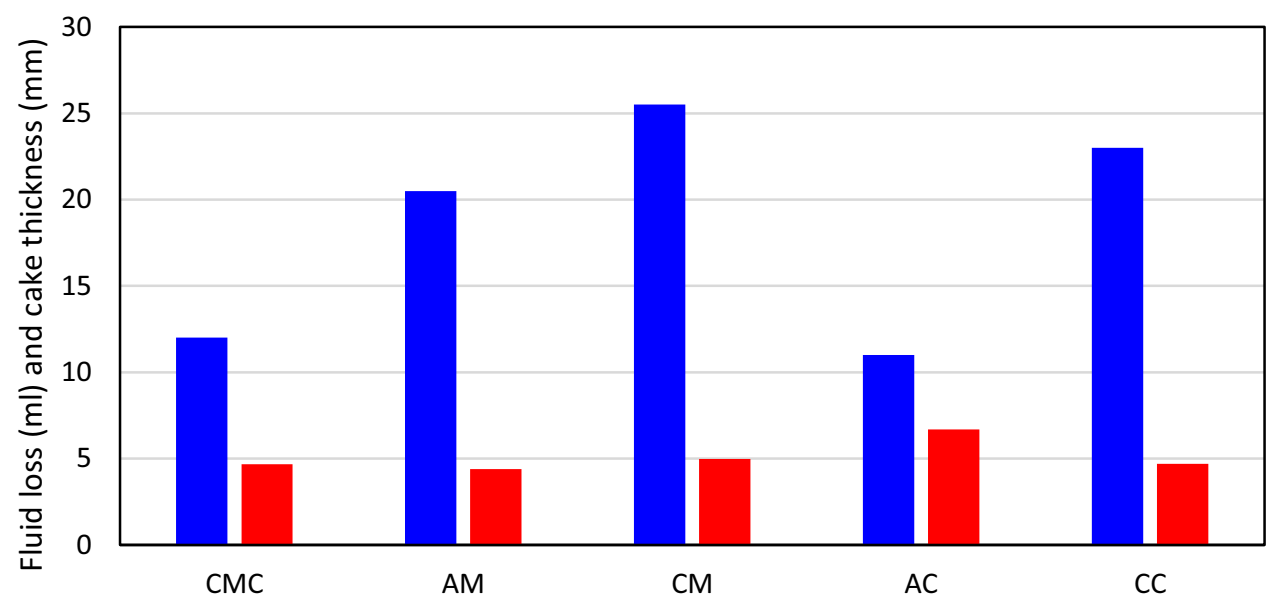

- HPHT filtration loss, $\mathrm{ml} \quad$ Filtrate cake thickness, $\mathrm{mm}$
Fig. 12 Filtrate characteristics, AHR, of mud samples added with $10 \mathrm{~g}$ of different modified starches water $\mathrm{pH}$ (7) to 8-9. However, despite the addition of modified starch, the $\mathrm{pH}$ value remained under 9; this suggests that modified starch can be used to reduce the mud acidity, which could otherwise lead to the corrosion of the bottom hole assembly equipment during drilling operations.

\section{Rheological model of the mud treated with modified starch}

The plots of shear stress and shear rate shown by Figs. 15,16,17,18 revealed that all the mud samples added with the different modified starches (AM, CM, AC, and CC) exhibited the characteristics of Bingham plastic model (linear curves), which is preferred for drilling muds, rather than a Newtonian fluid behaviour (straight lines). This proves that the formulated muds had acceptable flowing characteristics. The slope and the threshold stress denote, respectively, the $\mu_{p}$ and $Y_{P}$ of the mud.

The gradient of the Bingham plastic model, which is the ratio of shear stress to shear rate, denotes the level of mud viscosity. The plots showed a gentle gradient throughout the dial speed, indicating that the mud samples had the characteristic of least resistance to flow due to interparticle friction. Besides, the yield point and also the point where the fluid will start to flow can be determined from the plots. From the shape of the plot, the fluid shows the 
Fig. $13 \mathrm{pH}$ values of mud samples added with $5 \mathrm{~g}$ of different modified starches
$\mathrm{pH}$ value of the mud with 5 gram modified starch

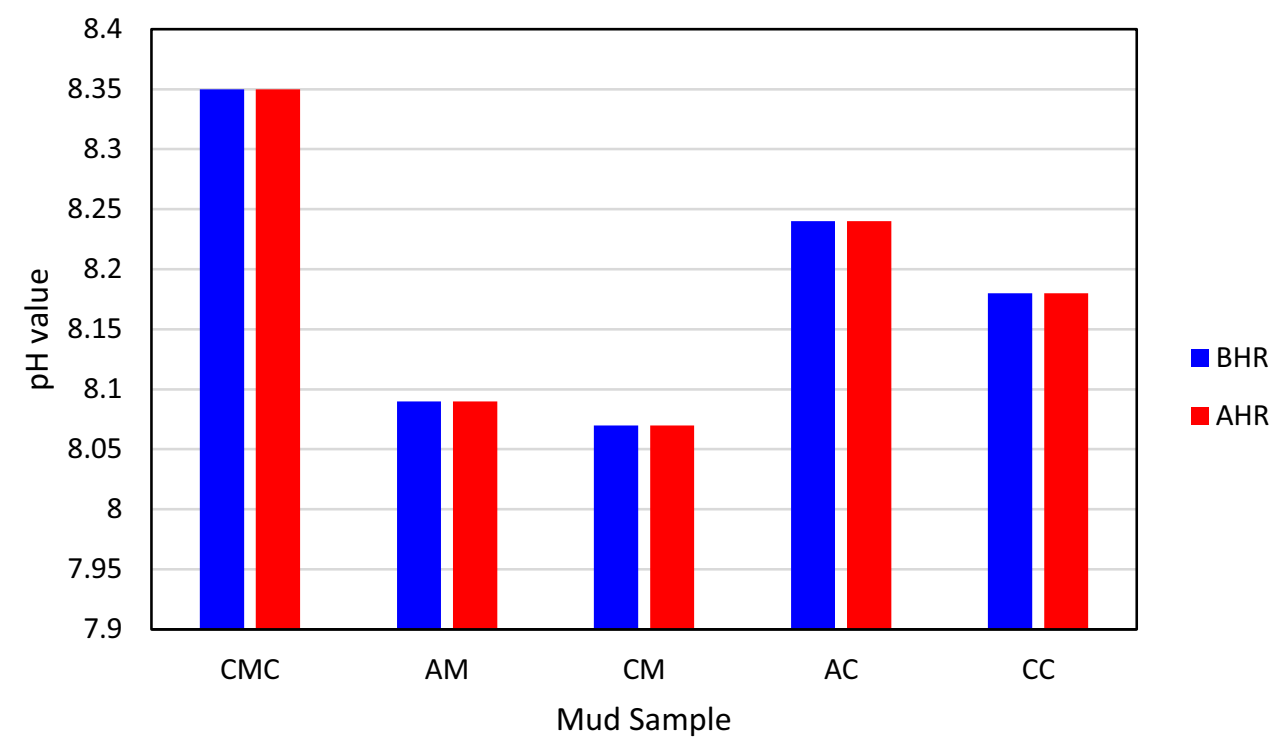

$\mathrm{pH}$ value of the mud with 10 gram of modified starch

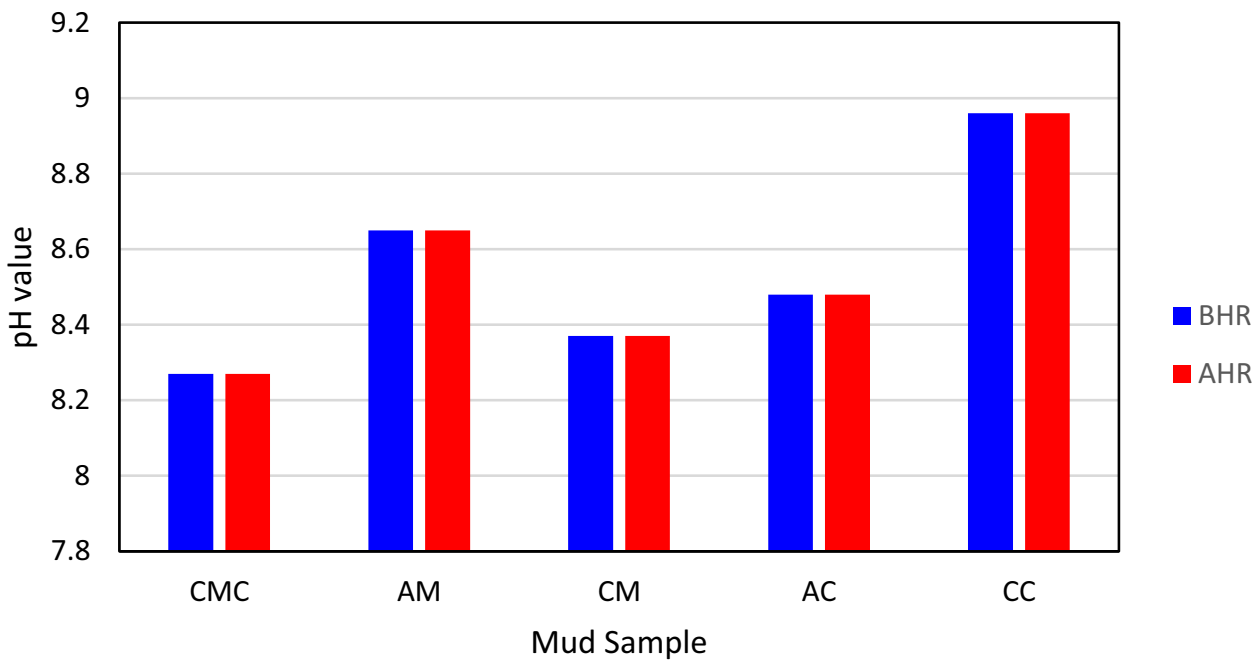

characteristic of pseudo-plastic fluid which is shear-thinning fluid because the viscosity is decreased when the shear rate is increased.

\section{Conclusions}

This study aimed to reduce the filtration loss and rheological properties of water-based mud treated with modified starch and to compare the achieved performance with that of the industrial fluid-loss agent CMC. The factors believed to influence both the filtration loss and rheological properties were the amylose and amylopectin contents. Results showed that the mud mixed with $5 \mathrm{~g}$ of AM met the API requirements in terms of both rheological properties and filtration-loss control. However, for the $10 \mathrm{~g}$ of modified starch, the sample with AC exhibited good rheological properties and filtration-loss control in agreement with the API specification. Under the HPHT condition, the mud samples treated with AM and AC showed the best rheology values, close to the API specification 13A 18th edition. Furthermore, the mud samples added with $5 \mathrm{~g}$ of $\mathrm{AM}$ or $10 \mathrm{~g}$ of $\mathrm{AC}$ exhibited the lowest filtrate volumes compared to those treated with the same amounts of modified starches. 
Fig. 15 Rheograms of mud samples added with $5 \mathrm{~g}$ of different modified starches

Fig. 16 Rheograms of mud samples added with $10 \mathrm{~g}$ of different modified starches
Rheogram of mud with 5 gram modified starch

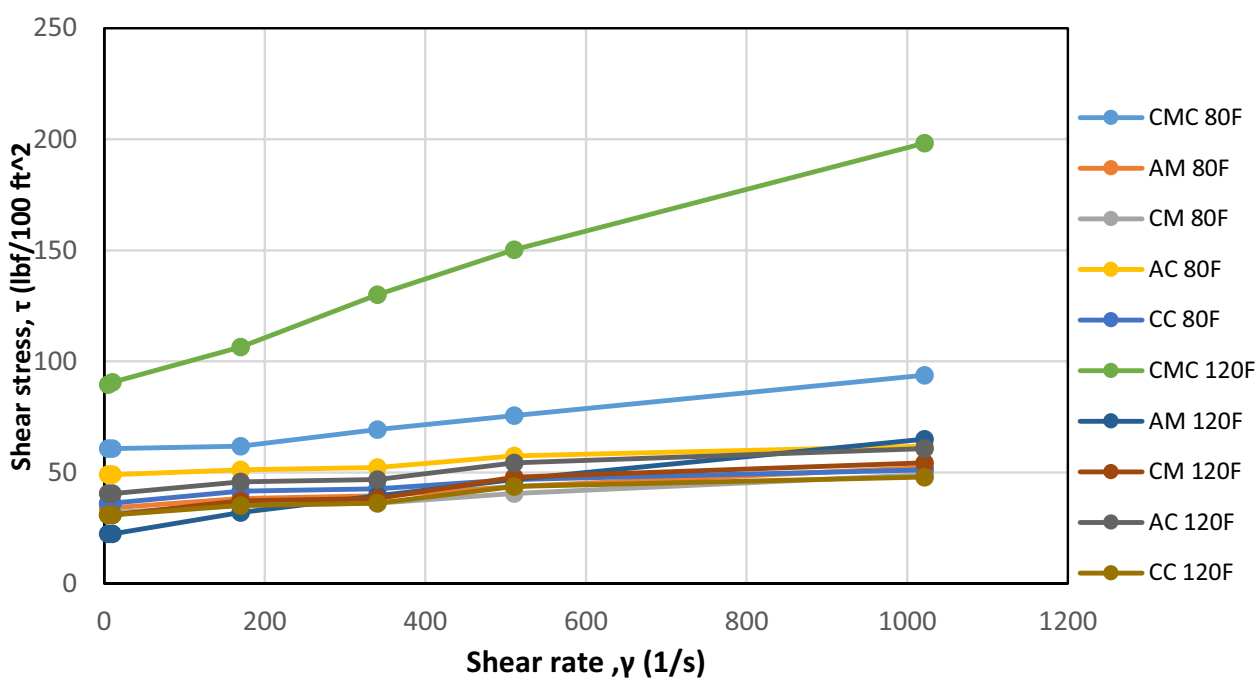

Rheogram of mud with 10 gram modified starch

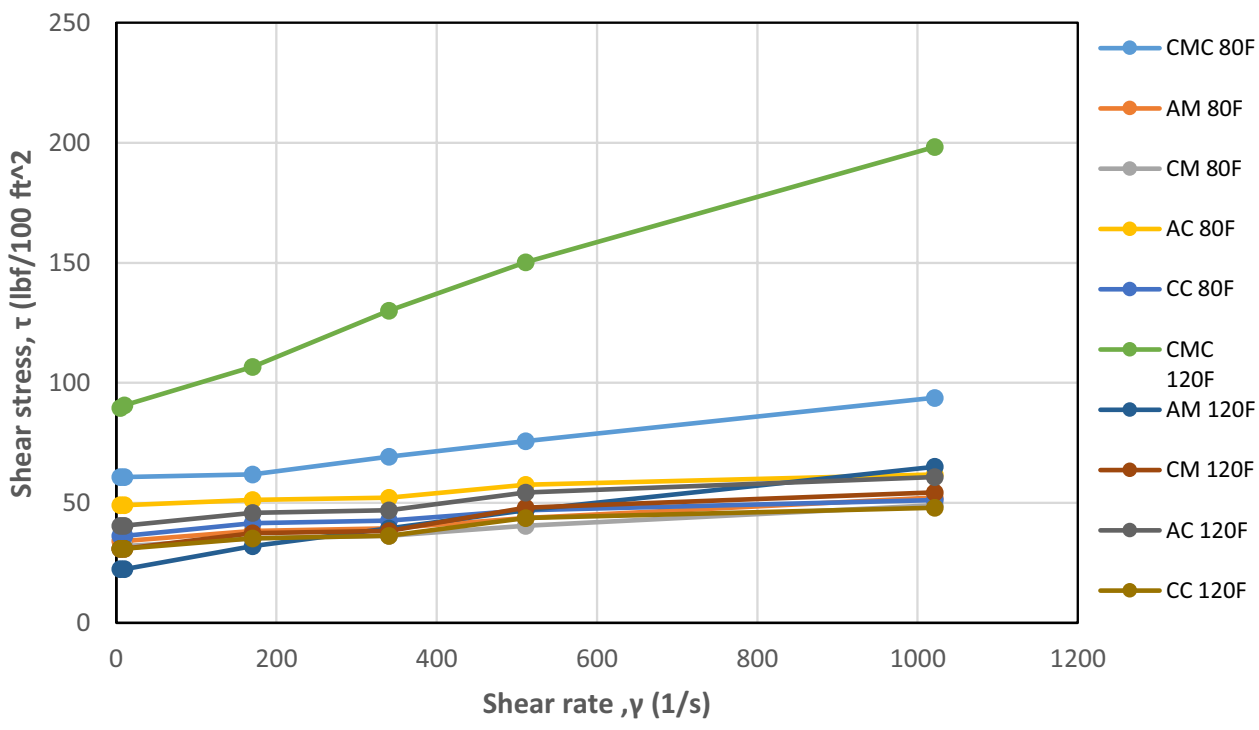


Fig. 17 Rheograms of mud samples added with $5 \mathrm{~g}$ of different modified starches

Fig. 18 Rheograms of mud samples added with $5 \mathrm{~g}$ of different modified starches

\section{Rheogram of mud with 5 gram modified starch}

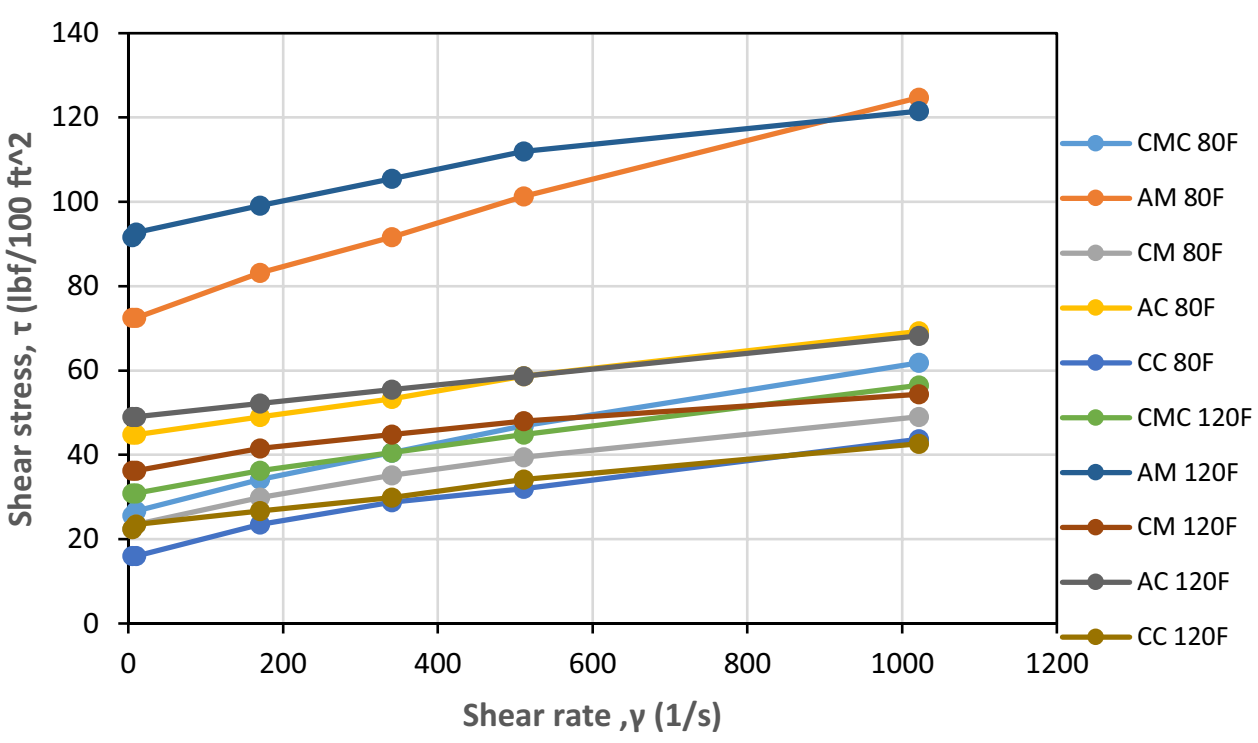

Rheogram of mud with 10 gram modified starch

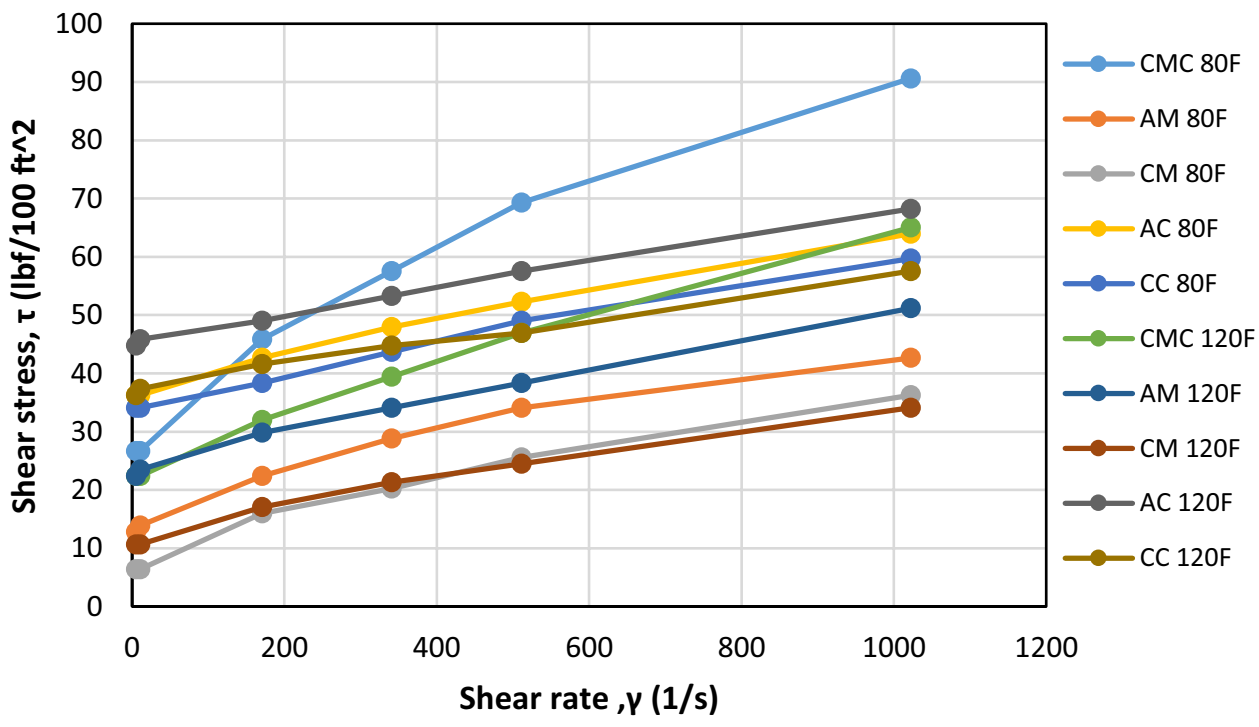

Acknowledgements The authors wish to appreciate Nigeria's Tertiary Education Trust Fund (TETFUND) for providing financial support (Intl. Grant 0153AB-E98) for this research project.

Funding The funders had no role in study design, data collection and analysis, decision to publish, or preparation of the manuscript.

\section{Compliance with ethical standards}

Conflict of interest On behalf of all the co-authors, the corresponding author states that there is no conflict of interest.
Open Access This article is licensed under a Creative Commons Attribution 4.0 International License, which permits use, sharing, adaptation, distribution and reproduction in any medium or format, as long as you give appropriate credit to the original author(s) and the source, provide a link to the Creative Commons licence, and indicate if changes were made. The images or other third party material in this article are included in the article's Creative Commons licence, unless indicated otherwise in a credit line to the material. If material is not included in the article's Creative Commons licence and your intended use is not permitted by statutory regulation or exceeds the permitted use, you will need to obtain permission directly from the copyright holder. To view a copy of this licence, visit http://creativecommons.org/licenses/by/4.0/. 


\section{References}

Aboulrous AA, Alsabagh AM, Abdou MI, Khalil AA, Ahmed HE (2014) Investigation of some locally water-soluble natural polymers as circulation loss control agents during oil fields drilling. Egypt J of Petr 23(1):27-34. https://doi.org/10.1016/j. ejpe.2014.02.005

American Petroleum Institute. (2009). API RP 13B-1. Recommended Practice for Field Testing Water-based Drilling Fluid.

American Petroleum Institute (2010). API Specification 13A $18^{\text {th }}$ Edition. Specification for Drilling Fluids-Specification and Testing.

Betancur AD, Chel GL, Cañizares HE (1997) Acetylation and characterization of Canavalia ensiformis starch. J Agric Food Chem 45(2):378-382

Harry TF, Joel OF, Ademiluyi FT, Oduola K (2016) Performance evaluation of local cassava starches with imported starch for drilling fluid. Am J Eng Res (AJER) 5(10):111-120

Khalil MI, Hashem A, Hebeish A (1990) Carboxymethylation of maize starch. Starch - Stärke 42(2):60-63
Manal AE (2010) Carboxymethylation of maize starch at mild conditions. CarbohydrPolym 79(4):875-881. https://doi. org/10.1016/j.carbpol.2009.10.013

Okumo I, Isehunwa SO (2007) Prediction of the viscosity of a waterbase mud treated with cassava starch and potash at varying temperatures using factorial design. Soc Petrol Eng. https://doi. org/10.2118/111886-MS

Sodhi NS, Singh N (2005) Characteristics of acetylated starches prepared using starches separated from different rice cultivars. J Food Eng 70(1):117-127

Sulaimon AA, Adeyemi BJ, Rahimi M (2017) Performance enhancement of selected vegetable oil as base fluid for drilling HPHT formation. J Petrol Sci Eng 152:49-59

Taiwo A, Joel O, Kazeem A (2011) Investigation of local polymer (Cassava Starches) as a substitute for imported sample in viscosity and fluid loss control of water-based drilling mud. ARJN J Eng Appl Sci 6(12):43-48

Publisher's Note Springer Nature remains neutral with regard to jurisdictional claims in published maps and institutional affiliations. 